\title{
Accuracy Analysis of Control Point Distribution for Different Terrain Types on Photogrammetric Block
}

\author{
Ahmet GUNTEL, Hakan KARABORK, Lutfiye KARASAKA
}

\begin{abstract}
Since the digital orthoimage and orthomosaic maps have come to be used more and more as the fundamental basis for many studies, the demand for such products has been gradually increasing in the recent years. Owing to the fact that they can be produced more rapidly and cheaper than the traditional topographic maps, the orthoimage maps are currently much in demand. The production accuracy of the orthoimage maps, obtained through aerial photographs or satellite images, has been an important research topic. The number and distribution of the ground control points have a significant bearing on the accuracy of aerial triangulation. Therefore, the accuracy of the orthoimage maps, being the end products, is related to the number and distribution of the ground control points within the block. This study has aimed to study the influence of the number and distribution of ground control points and check points on the accuracy of aerial triangulation by using different GNSS/IMU systems. Five different configurations have been designed depending on the distribution of the ground control and check points within rectangular shaped blocks in different combinations and numbers. Such configurations were then tested in different types of terrain such as forest lands, residential and agricultural areas. The objective of the study was to identify the most ideal geodesic structure and the most accurate photogrammetric triangulation adjustment suitable for various different systems based on such terrain classification. The results were evaluated based on the ASPRS accuracy standards.
\end{abstract}

Keywords: accuracy; aerial triangulation; bundle adjustment; GCPs distribution

\section{INTRODUCTION}

The historical development of the scientific field of photogrammetry -which enables the performance of such inquiries as coordinate, distance, area and volume through photographs without establishing physical contact with the object of inquiry- is traced back to 1480 when the concepts of perspective and projection were first introduced [14]. The very first aerial photographs that were captured by using a kite or balloon are now replaced by digital images captured with large-format digital cameras. The biggest advantage of the digital aerial cameras is the large-format panchromatic integrated images depending on the location of the camera cones. Therefore wider areas can be photographed in higher resolution and in a short time. The end product obtained from the aerial triangulation is that of the georeferenced digital images and three-dimensional coordinate data. With this method, also known as direct georeferencing, the orientation parameters of the images in the moment of exposure are directly obtained by significantly reducing the data acquisition and processing costs $[8,21,23,25$, 27]. However the results obtained present systematic errors [24]. In order to evaluate the accuracy or quality of a block adjustment and eliminate the systematic errors therein, the ground control points within the object space are required to be established [3]. The studies thus far conducted seem to suggest that the systematic errors can be eliminated by correcting the navigation sensors GPS/INS, calibration, datum or projection details and by introducing ground control points that are distributed within the block in a geometrically consistent fashion [22, $27,21,3]$. Aerial triangulation networks are a sum total of mostly large and irregular shaped different geometrical blocks that consist of different flight configurations. Therefore, the distribution and number of ground control points in aerial triangulation within the block has been

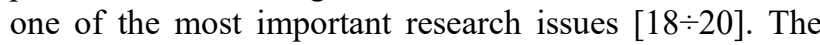
influence of the distribution and number of ground control points on geometrical accuracy in various different flight plans, in particular, has been tested by using additional parameters in large-format cameras with or without selfcalibration $[5,6,16,24]$. The studies conducted suggest that the self-calibration parameter sets affect the overall quality of many products, obtained from block adjustment accuracy to automatic digital elevation model generation, in a positive way [2].

The accuracy of a block is associated with the number of ground control points and the accuracy of such points. The concept of block accuracy is classified as theoretical block accuracy and experimental block accuracy. While the theoretical block accuracy is obtained through the covariance matrices of the adjusted ground control points, the experimental accuracy is obtained by using check points. In experimental block accuracy, the root mean square value is calculated after having established the difference between the adjusted ground control points and the real values of such points [4]. Depending on the block shapes, distribution within the appropriate geometry and at the optimum number of the ground control points and check points has a significant bearing on the GNSS/IMU aided aero triangulation block adjustment results. GNNS/IMU sensors are particularly advantageous in such difficult terrains or in situations where overlap ratio is inadequate in terms of reducing the number of tie points [30]. The studies in the literature point out that having one ground control point in the centre of the block and four points on the corners of the block may be enough for mathematically analyzing whole block [26, 27, 30]. However, in some cases, the size and geometry of the block or the terrain class of the block being studied may not make it possible to establish the optimum ground points and the condition of point distribution that is required for mathematically analysing the aerial triangulation. The literature includes various studies conducted on various different terrain classes and different block analyses for tackling the current problems. The examples of such studies include the mid and small scale projects based on weak patterned aerial photographs captured in deserts under extremely hot and hazy weather 
conditions [18], the influence of arid environmental conditions on systematic image errors (by using ground control and check points) [9], block adjustment studies on coastal areas where ground control points could scarcely be established or not established at all [17, 29]. The purpose of this study is to study the influence of point distribution configurations on block adjustment within the blocks that are formed in various terrain classes such as forestlands, residential and agricultural areas. The images have been captured by using DMCII-230 and Ultracam Vexcel XP make digital aerial cameras. While the DMCII-230 digital aerial camera and DUSS 5 have been used as positioning and navigation sensors, the GNSS systems, called NUSS 4, have been used for the Ultracam Vexcel XP digital aerial camera. Each terrain class has been evaluated based on five different ground control point distribution models. The effect of point distribution on block adjustment has been evaluated for different terrain types by taking into account the differences of the GNSS/IMU systems used in the application.

\section{MATERIALS AND METHOD}

\subsection{Study Area}

The city of Istanbul - having a geographically significant place within the boundaries of Turkey- has been chosen as the test area. Istanbul is located 280.017 and 290.917 to the east and 410.55 and 400.467 to the north (Fig. 1).

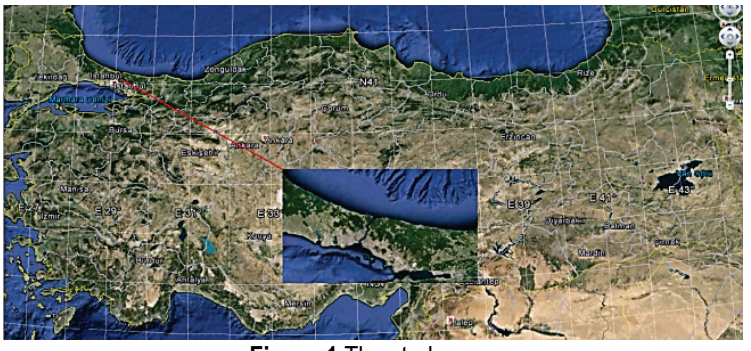

Figure 1 The study area

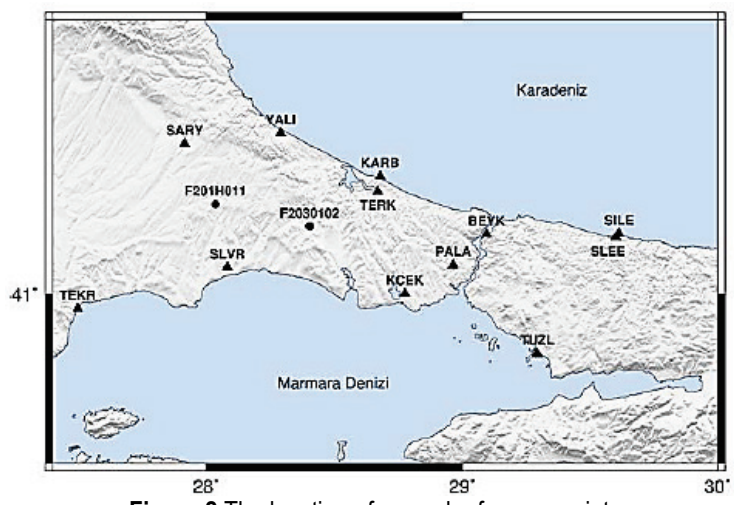

Figure 2 The location of ground reference points

The study area to be tested has been classified as forestland, agricultural and residential areas based on its terrain class and size. In addition to the chosen terrain classes, attention is given to the elevation of terrain, distribution and location of the ground control points. The minimum and maximum altitudes of the small test areas that are classified within the study area (blocks) above the sea level are $70 \mathrm{~m}$ and $360 \mathrm{~m}$ respectively. While a total of 145 ground control points has been established in the selected test areas, each block had approximately 24 ground control points. In order to obtain the positional data in a more reliable way, care has been taken to ensure that the distance between the ground reference point and the airplane was always maintained at $25 \mathrm{~km}$ and that precise ephemeris data was used in evaluating the observations. Moreover, in addition to the 1s interval GNSS records of the TUSAGA Active Stations, two ground reference points have been established in the area of study (Fig. 2).

\subsection{Imaging and Navigation Sensor}

Digital aerial cameras are divided into two groups in terms of their imaging geometry, namely frame based array type cameras and line scan-push broom cameras. Another grouping includes large, mid and small format cameras based on their CCD sensor size and pixel resolution. In this study, we have used DMCII-230 and UltraCamXP make large format digital aerial cameras. While the DMCII-230 digital aerial camera and DUSS 5 have been used as positioning and navigation sensors; the GNSS systems, called NUSS 4, have been used for the Ultracam Vexcel XP digital aerial camera.

\section{$2.3 \mathrm{DMCll}-230$}

The DMC II 230 is using the DALSA 252 megapixel CCD DALSA 252 Megapixel CCD-array with $17216 \mathrm{x}$ 14656 pixels $(96.4 \times 82.1 \mathrm{~mm})$. Known as the "230" model, this particular camera is unable to use the full size of the CCD sensors due to the current optical camera combination of the DMC II [15]. DMC II-230 is vertically positioned to the flight direction and has parallel panchromatic pixel resolution of $14144 \times 15552$, focus distance of $92 \mathrm{~mm}$, pixel size of $5.6 \mu \mathrm{m}, b / h$ ratio of 0.34 , color channels R, G, B, NIR, radiometric resolution of 14 bits and exposure period of 1,8 seconds. Considering the technical features of the camera, an aerial imaging process to be performed at the GSD distance of $10 \mathrm{~cm}$ can be maintained at the flight altitude of 1600 to 1960 meters by taking into account the flight altitude ground plus 1785 $\mathrm{m}$ as well as the flight boundary of $\pm 10 \%$. This provides a flexibility that will allow the flight to maintain its course without having to alter its flight altitude very often during the flights planned to be performed on the east to west direction within the Istanbul project area, which is rarely observed within the same colon at 360 meter flight altitude. The base/flying-height ratio of 0.35 ensures significant altitude accuracy compared to other cameras.

\subsection{UltracamXP}

UltracamXP is a large format digital aerial camera. Similar to the UltracamD and UltracamX cameras, the camera exposes the images through 9 CCD sensors installed in 4 panchromatic camera cones. The UltraCamXP large format digital aerial camera works based on the syntopic imaging principle meaning each camera cone exposes the image within the same exposure station [11]. It is vertically positioned to the flight direction and has parallel panchromatic pixel resolution of $17310 \times 11310$, focus distance of $100 \mathrm{~mm}$, pixel size of 6 
$\mu \mathrm{m}, \mathrm{b} / \mathrm{h}$ ratio of 0.2 , color channels $\mathrm{R}, \mathrm{G}, \mathrm{B}, \mathrm{NIR}$, radiometric resolution of 14 bits and exposure period of 2 seconds. Considering the technical features of the camera, an aerial imaging process to be performed at the GSD distance of $10 \mathrm{~cm}$ can be maintained at the flight altitude of 1500 to 1833 meters by taking into account the flight altitude ground plus $1,666 \mathrm{~m}$ as well as the flight boundary of $\pm 10 \%$.

\subsection{Terrestrial Geodetic Survey}

A total of 145 ground control points have been established in the area. Geodesic measurements have been performed by employing static measurement method and using the Leica AX1202 and ATX1230 GNSS make receivers. As a result of the observations, the $\mathrm{C} 1$ and $\mathrm{C} 2$ degree points have been evaluated together (see Figure 3), while the C3degree point has been evaluated separately. In order to be able to conclude that the influence of the GNSS evaluations was equal, the standards of the ground control points in the photogrammetric triangulation were taken as $\mathrm{x} / \mathrm{y}=0.03 \mathrm{~cm}, \mathrm{z}=0.05 \mathrm{~cm}$ in each block and $/$ or version.

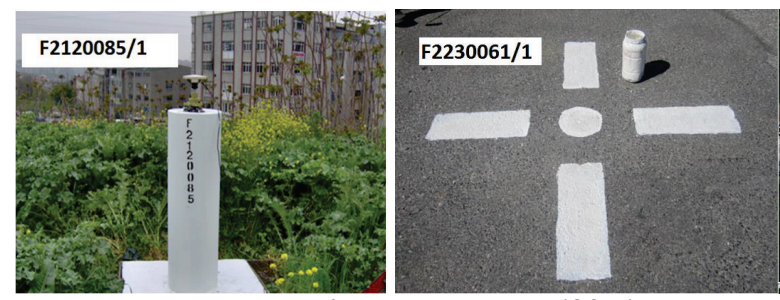

Figure 3 Detail of ground control points (GCPs)

\subsection{Mathematical Model of Aerial Triangulation}

Firstly developed and used for military applications, the GPS technology has been made available for civilian use from 1980s onwards and started to be used in GPS based aerial triangulation applications. The end products obtained today from the new INS/GPS sensors -developed based on Micro Electro Mechanical System (MEMS) technology in contrast to the traditional aerial triangulation techniques - are those of the georeferenced digital images and three dimensional coordinate data. This INS/GPS based method is called directly georeferenced and the orientation parameters of images are obtained directly in real time with simple geometrical intersection methods by using image coordinates of tie points.

Eq. (1) and Fig. 4 summarize the mathematical model of the GNSS/INS based aerial triangulation.

$r_{i}^{m}=r(t)_{I N S / G P S}^{m}+R(t)_{b}^{m}\left(s_{i} R_{c}^{b} r_{i}^{c}+r_{I N S}^{c}-r_{I N S}^{G P S}\right)$

Where: $r_{i}^{m}$ - refers to the unknown (i) 3B coordinate vector of an object point in the map reference system; $r(t)_{I N S / G P S}^{m}$ - refers to the coordinate vector in the map reference system of the interpolated navigation sensor (INS/GPS); $s_{i}$ - refers to the scale coefficient determined through stereo techniques; $(t)$ - refers to the moment of exposure; $R_{c}^{b}$ - refers to the rotation matrix between the camera reference system and the INS reference system (determined through calibration); $r_{i}^{c}-$ refers to the object whose position vector is measured in the camera reference system; $r_{I N S}^{c}$ - refers to the vector between the IMU center and principal camera point (determined through calibration); $r_{I N S}^{G P S}$ - refers to the vector between the IMU center and the GPS phase center (determined through calibration).

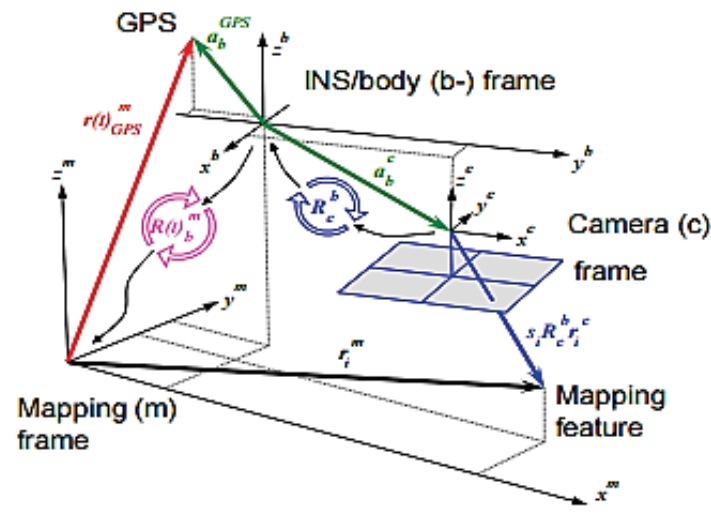

Figure 4 Concept of direct georeferencing model [7]

In order to apply the direct georeferencing presented in Equation 1, the boresight angles and Lever-Arm offset should be determined. In order to accurately estimate the ground coordinates of object points through direct georeferencing method, the IMU sensor center and the camera perspective center should be physically in the same position. However, this is theoretically impossible, the misalignments between the IMU center and the optical center of camera are determined by way of calibration. Such values defined as misalignment angles between the IMU and digital camera are those of the IMU boresight angles. Another vector determined through calibration is Lever-Arm. Lever-Arm represents the relative position of a sensor in comparison to another sensor. When the camera perspective center is taken as the point of reference, there are two lever-arm vectors to be measured [12]. The first one is the positional vector between the GPS phase center and IMU center represented as $r_{I N S}^{G P S}$, while the other one is the lever-arm offset vector between the lever-arm camera perspective center and IMU coordinate system represented as $r_{I N S}^{c}[10]$. When the exact location of the GPS phase center and the perspective center of the imaging sensors are considered the lever-arm GPS/IMU is merely an approximate value achieved through correct installation or the use of total station [13].

In order to determine the difference vector between the camera and the GNSS antenna, the Lever-Arm calibration measurements have been performed through TOPCON $3107 \mathrm{~N}$ laser total station. As a result of the measurements, the difference vector has been detected between the camera and the GNSS antenna. The values found for the Ultracam XP are presented in Tab. 1.

Table 1 Lever-Arm correction value for Ultracam XP and Cessna T206

\begin{tabular}{|c|c|c|}
\hline$X(\mathrm{~m})$ & $Y(\mathrm{~m})$ & $Z(\mathrm{~m})$ \\
\hline 0.0092 & 0.012 & -0.0772 \\
\hline
\end{tabular}

Prior to embarking on the flight scheduled for the DMCII-230 and Ultracam XP cameras, the Boresight calibration values obtained from the Silivri test area were estimated. The adjustment procedure was performed only 
by using ground control points in four horizontal columns and four vertical columns. As a result of the adjustment, the boresight calibration angles determined for the DMCII-230 and Ultracam XP cameras are presented in Tab. 2.

Table 2 Boresight calibration value DMC II-230 and Ultracam XP

\begin{tabular}{|l|c|c|c|}
\hline & Omega & Phi & Kappha \\
\hline DMC II-230 & -0.0162 & -0.0776 & -0.3493 \\
\hline Ultracam XP & 0.0307 & -0.3344 & 0.0121 \\
\hline
\end{tabular}

\section{RESULTS AND DISCUSSION}

One of the most important steps in an extensive GNNS/INS based aero triangulation study is the preparation of flight plans. This procedure, originally starting with the block planning, includes many aspects that need to be taken into consideration. The aspects that are taken into consideration while scheduling an aerotriangulation flight plan include the topographic structure of the region, the geometrical properties of the project site, the photogrammetric block structure, the frame size of the camera to be used, ground sampling distance (GSD), base length, forward and sidelap overlap ratios. Within the scope of the present study, the flight plan is prepared on the $1 / 25000$ scale maps.

Due to the fact that ground sampling distance was 10 $\mathrm{cm}$, and that focus distance value of the DMCII-230 and Ultracam XP aerial cameras were close to one another, the average flight altitude was set as $1650 \mathrm{~m}$ (Tab. 3). All the flights were planned in the east-west direction.

The blocks to be studied within the scope of this study were classified based on the number of ground control points, terrain class and size. The knowledge regarding blocks such as the camera, number of ground control points, block size and block geometry are given in Tab. 4. The image matching of the blocks was performed automatically by using the Z/I Automatic triangulation software. After having summed up the automatic (tie/pass) points, the points affecting the relative accuracy were eliminated. The empty spots within the block were manually matched. The summation process for photogrammetric triangulation in each block was carried out by following those steps. The number of columns and the respective blocks within each terrain type that have been subject to evaluation are as follows: 9 columns for the blocks 9 and 109 within the forestlands; 10 columns for the block 73 and 8 columns for the block 86 within the residential areas; 8 columns for the block 33 and 11 columns for the block 103 within the agricultural areas.

Table 3 The altitude for DMCII-230 and Ultracam XP

\begin{tabular}{|l|c|c|}
\hline \multicolumn{1}{|c|}{ Parameters } & DMCII-230 & Ultracam XP \\
\hline Photograph height (pixel) & 15552 & 17310 \\
\hline Photograph width (pixel) & 14144 & 11310 \\
\hline Pixel size $(\mu)$ & 5.6 & 6 \\
\hline Focus distance(mm) & 92 & 100.5 \\
\hline Real dimension height $(\mathrm{mm})$ & 87.09 & 103.86 \\
\hline Real dimension width $(\mathrm{mm})$ & 79.21 & 67.86 \\
\hline GSD $(\mathrm{cm})$ & 10 & 10 \\
\hline Image scale & 17857 & 16667 \\
\hline Flight altitude & 1643 & 1675 \\
\hline Real ground lengthwise $(\mathrm{m})$ & 1555.2 & 1731 \\
\hline Real ground widthwise $(\mathrm{m})$ & 1414.4 & 1131 \\
\hline Forward overlap & 70 & 70 \\
\hline Sidelap overlap & 32 & 32 \\
\hline a (lengthwise base) $(\mathrm{m})$ & 424.32 & 339.3 \\
\hline b (widthwise base) $(\mathrm{m})$ & 1057.536 & 1177.08 \\
\hline
\end{tabular}

Table 4 The land classification

\begin{tabular}{|c|c|c|c|c|c|c|c|}
\hline Land class & Block number/column number & Region & Camera & GNSS/IMU & Block area $(\mathrm{km})$ & Block geometry & Number of GCPs \\
\hline \multirow{2}{*}{ Forestland } & $9 / 9$ & Europe & DMC II-230 & Class5 & 63.83 & Rectangular & 22 \\
\hline & $109 / 9$ & Asia & UltracamXP & Class4 & 64.14 & Rectangular & 20 \\
\hline \multirow{2}{*}{ Residential } & $73 / 10$ & Europe & DMC II-230 & Class5 & 52.52 & Rectangular & 16 \\
\hline & $86 / 8$ & Asia & UltracamXP & Class4 & 61.32 & Rectangular & 24 \\
\hline \multirow{2}{*}{ Farmland } & $33 / 8$ & Europe & DMC II-230 & Class5 & 64.10 & Rectangular & 36 \\
\hline & $103 / 11$ & Asia & UltracamXP & Class4 & 73.27 & Rectangular & 27 \\
\hline
\end{tabular}

GNSS based aerial triangulation is a method that is used for analyzing the $3 \mathrm{D}$ coordinates of the objects along with the exterior orientation parameters of images. The positions of the camera stations are regarded as weighted observations that are determined by kinematic GPS-aided photogrammetric work. The most common analysis of aerial triangulation based-GPS is the bundle block adjustment [28]. The ground control points are required for resolving the datum issues and eliminating the systematic errors in GPS observations, and the distribution of such points inside the block and on its corners affects the adjustment accuracy in the GPS-aided aerial triangulation. Ackermann [1] has summarized the characteristic distribution of a block containing ground control points as (a) diagonal lines placed at the beginning and end of an adjustment block and 4 full ground control points placed on each corner of the block, (b) in addition to the 4 full ground control points on the block corners, distribution of altitude control points entered in a single line at the beginning and end of a block.
In this study, we have studied the effect of the positional distribution and number of ground control points on the adjustment accuracy in various different terrain types by using different GNSS/IMU systems in the blocks with the same geometrical shape. All the blocks have been adjusted according to the same version within their own respective classification. The distribution and number of ground control points within the block has been evaluated in different test areas. Weighted ground control points have been employed in all versions. The points remaining outside the designated ground control points have been evaluated as check points.

Five different configurations have been prepared for the distribution of the ground control points for the blocks in different terrain types within the designated area of study (forestlands, residence and agricultural areas). The self-calibration could not be performed due to the insufficient number of matching points within the block 9 and block 109 that are characterized as forestlands. The self-calibration with 12 additional parameters was applied 
in the adjustment of the residence area blocks (block 73 and block 86) and agricultural area blocks (block 33 and block 103. While the block 9, block 73 and block 33 were evaluated through Class 5 GNSS/IMU observations, the other remaining blocks were evaluated through Class 4 GNSS/IMU observations. In accordance with the five different configurations thus planned, the details regarding the distribution of the ground control points and check points inside the block and on the corners of the block in various numbers as well as the general block data are provided in Tab. 5 .

Block configurations are summarized as follows:

Test_i. Block Corner Points

Test_ii. Vertical Block Edges

Test iii. Horizontal Block Edges

Test_iv. Center of the Block

Test_v. Block Corners-Edges and Center.

Table 5 Properties of test blocks

\begin{tabular}{|c|c|c|c|c|c|c|}
\hline & Parameter & Test_i & Test_ii & Test_iii & Test_iv & Test_v \\
\hline \multirow{5}{*}{$\begin{array}{l}a \\
\frac{y}{0} \\
\frac{o}{m}\end{array}$} & GCPs & 5 & 7 & 9 & 7 & 7 \\
\hline & Number of check points & 16 & 14 & 12 & 15 & 12 \\
\hline & Strips & 9 & 9 & 9 & 9 & 9 \\
\hline & GPS receiver & Class 5 & Class 5 & Class 5 & Class 5 & Class 5 \\
\hline & Type of terrain & Forest & Forest & Forest & Forest & Forest \\
\hline \multirow{5}{*}{$\begin{array}{l}\stackrel{\partial}{\circ} \\
\frac{y^{\prime}}{\ddot{D}} \\
\frac{0}{\infty}\end{array}$} & GCPs & 5 & 7 & 9 & 6 & 9 \\
\hline & Number of check points & 14 & 11 & 10 & 13 & 12 \\
\hline & Strips & 9 & 9 & 9 & 9 & 9 \\
\hline & GPS receiver & Class 4 & Class 4 & Class 4 & Class 4 & Class 4 \\
\hline & Type of terrain & Forest & Forest & Forest & Forest & Forest \\
\hline \multirow{5}{*}{$\begin{array}{l}\stackrel{2}{a} \\
\frac{y^{\prime}}{0} \\
\frac{0}{\infty}\end{array}$} & GCPs & 5 & 7 & 9 & 6 & 8 \\
\hline & Number of check points & 10 & 15 & 6 & 16 & 14 \\
\hline & Strips & 10 & 10 & 10 & 10 & 10 \\
\hline & GPS receiver & Class 5 & Class 5 & Class 5 & Class 5 & Class 5 \\
\hline & Type of terrain & Residental & Residental & Residental & Residental & Residental \\
\hline \multirow{5}{*}{ 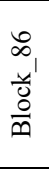 } & GCPs & 5 & 7 & 9 & 6 & 3 \\
\hline & Number of check points & 17 & 8 & 13 & 9 & 12 \\
\hline & Strips & 8 & 8 & 8 & 8 & 8 \\
\hline & GPS receiver & Class 4 & Class 4 & Class 4 & Class 4 & Class 4 \\
\hline & Type of terrain & Residental & Residental & Residental & Residental & Residental \\
\hline & Parameter & Test_i & Test_ii & Test_iii & Test_iv & Test_v \\
\hline \multirow{5}{*}{$\begin{array}{l}m \\
m \\
\frac{v}{0} \\
\frac{0}{m}\end{array}$} & GCPs & 5 & 7 & 9 & 6 & 12 \\
\hline & Number of check points & 13 & 11 & 9 & 12 & 6 \\
\hline & Strips & 8 & 8 & 8 & 8 & 8 \\
\hline & GPS receiver & Class 5 & Class 5 & Class 5 & Class 5 & Class 5 \\
\hline & Type of terrain & Farmland & Farmland & Farmland & Farmland & Farmland \\
\hline \multirow{5}{*}{$\begin{array}{l}\hat{0} \\
\frac{y}{d} \\
\frac{0}{m}\end{array}$} & GCPs & 5 & 7 & 9 & 6 & 12 \\
\hline & Number of check points & 20 & 18 & 16 & 19 & 12 \\
\hline & Strips & 11 & 11 & 11 & 11 & 11 \\
\hline & GPS receiver & Class 4 & Class 4 & Class 4 & Class 4 & Class 4 \\
\hline & Type of terrain & Farmland & Farmland & Farmland & Farmland & Farmland \\
\hline
\end{tabular}

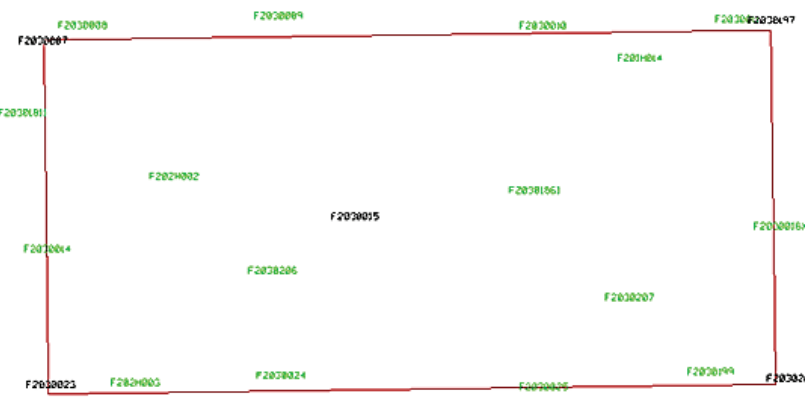

Figure 5 Distribution of GCPs on block corners

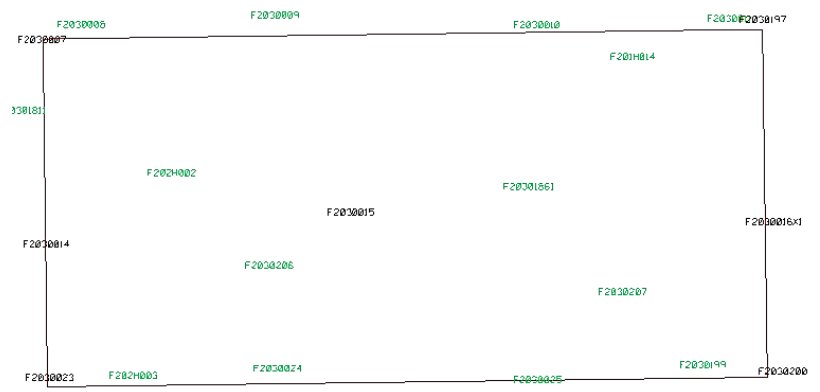

Figure 6 Distribution of GCPs on block vertical edge
The standard deviations and orientation unknowns of the ground control points and check points have been used for evaluating different block configurations. According to the block adjustment results, Tab. 6 presents the root mean square errors of the ground control and check points and the standard deviation values of the object point coordinates pertaining to the blocks. For all configurations, the block adjustment results have been found as follows: $1.6 \mu$ sigma for block $9 ; 1.9 \mu$ sigma for block $109 ; 1.3 \mu$ sigma for block $73 ; 1.4 \mu$ for block 86 ; $1.3 \mu$ sigma for block $33 ; 1.5 \mu$ sigma for block 103 .

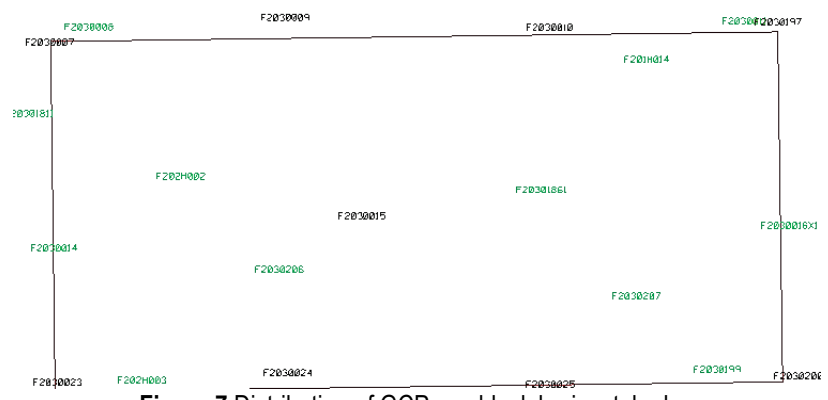

Figure 7 Distribution of GCPs on block horizontal edge 


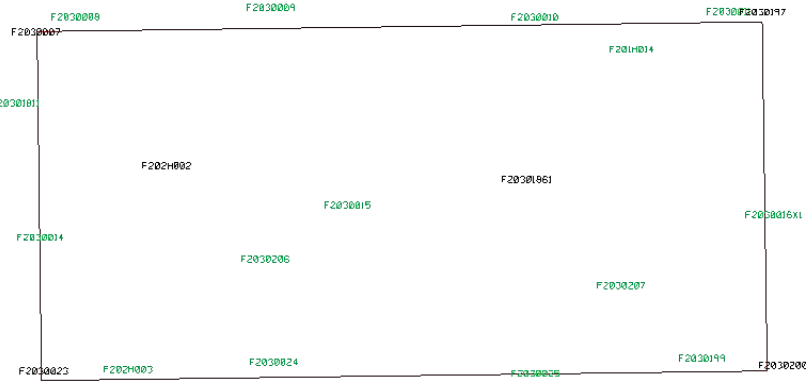

Figure 8 Distribution of GCPs on block centre

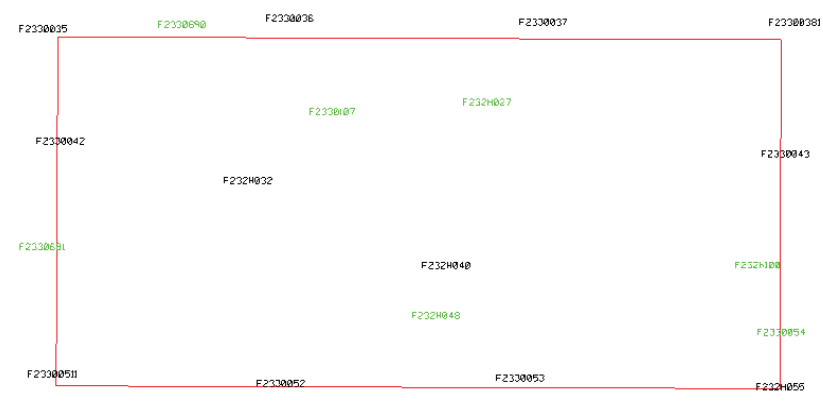

Figure 9 Distribution of GCPs on block corners, edges and centre

Table 6 RMS of the GCPs and ChPs and the standard deviation values of the object point coordinates

\begin{tabular}{|c|c|c|c|c|c|c|c|c|c|c|c|c|c|c|c|c|c|c|c|c|c|}
\hline \multirow{8}{*}{ 要 } & & \multicolumn{4}{|c|}{ Test_ $\mathrm{i}$} & \multicolumn{4}{|c|}{ Test_ii } & \multicolumn{4}{|c|}{ Test_iii } & \multicolumn{4}{|c|}{ Test_iv } & \multicolumn{4}{|c|}{ Test_v } \\
\hline & Parameter & X/Omega & Y/Phi & Z / Kappa & $X Y$ & X/Omega & $\mathrm{Y} / \mathrm{Phi}$ & Z / Kappa & $X Y$ & X/Omega & Y/Phi & Z / Kappa & $\mathrm{XY}$ & $\mathrm{X} /$ Omeg & $\mathrm{Y} / \mathrm{Phi}$ & Z / Kappa & $X Y$ & X/Omega & Y/Phi & Z / Kappa & $X Y$ \\
\hline & \begin{tabular}{|l} 
RMS Control \\
\end{tabular} & 0.016 & 0.006 & 0.003 & 0.012 & \begin{tabular}{|l|}
0.016 \\
\end{tabular} & 0.009 & 0.005 & 0.013 & 0.021 & 0.014 & 0.015 & 0.018 & 0.018 & 0.007 & 0.005 & 0.014 & 0.022 & 0.027 & 0.012 & 0.025 \\
\hline & RMS Check & 0.074 & 0.106 & 0.146 & 0.091 & 0.086 & 0.106 & 0.132 & 0.097 & 0.057 & 0.109 & 0.087 & 0.087 & 0.075 & 0.102 & 0.144 & 0.089 & 0.069 & 0.076 & 0.086 & 0.072 \\
\hline & RMS Limits & 0.04 & 0.04 & 0.04 & & 0.04 & 0.04 & 0.04 & & 0.04 & 0.04 & 0.04 & & 0.04 & 0.04 & 0.04 & & 0.04 & 0.04 & 0.04 & \\
\hline & Max Ground Residual & 0.023 & 0.011 & 0.005 & & 0.025 & 0.02 & 0.009 & & 0.029 & 0.023 & 0.029 & & 0.028 & 0.01 & 0.008 & & 0.044 & 0.07 & 0.027 & \\
\hline & Mean Std Dev Object & 0.02 & 0.022 & 0.072 & & 0.019 & 0.02 & 0.067 & & 0.019 & 0.02 & 0.068 & & 0.02 & 0.021 & 0.069 & & 0.018 & 0.019 & 0.064 & \\
\hline & Sigma & \multicolumn{4}{|c|}{$1.6 \mu \mathrm{m}$} & \multicolumn{4}{|c|}{$1.6 \mu \mathrm{m}$} & \multicolumn{4}{|c|}{$1.6 \mu \mathrm{m}$} & \multicolumn{4}{|c|}{$1.6 \mu \mathrm{m}$} & \multicolumn{4}{|c|}{$1.6 \mu \mathrm{m}$} \\
\hline \multirow{6}{*}{ 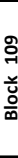 } & RMS Control & 0 & \begin{tabular}{l|l|l}
0 & \\
\end{tabular} & 0 & 0 & 0 & 0 & 0.001 & 0 & 0 & 0 & 0 & 0 & 0 & 0 & 0 & 0 & 0 & 0 & 0 & 0 \\
\hline & \begin{tabular}{|l|} 
RMS Check \\
\end{tabular} & 0.062 & 0.056 & 0.145 & 0.059 & 0.07 & 0.046 & 0.095 & 0.059 & 0.049 & 0.064 & 0.164 & 0.057 & 0 & 0 & 0 & 0 & 0.047 & 0.051 & 0.124 & 0.049 \\
\hline & RMS Limits & 0.04 & 0.04 & 0.05 & & 0.04 & 0.04 & 0.05 & & 0.04 & 0.04 & 0.05 & & 0.065 & 0.051 & 0.148 & 0.059 & 0.04 & 0.04 & 0.05 & \\
\hline & Max Ground Residual & 0.001 & 0 & 0 & & 0.001 & 0 & 0.001 & & 0.001 & 0 & 0.001 & & 0.04 & 0.04 & 0.05 & & 0.001 & 0.001 & 0.001 & \\
\hline & Mean Std Dev Object & 0.021 & 0.025 & 0.082 & & 0.02 & 0.025 & 0.078 & & 0.019 & 0.024 & 0.079 & & 0.12 & 0.12 & 0.15 & & 0.019 & 0.024 & 0.075 & \\
\hline & Sigma & \multirow{2}{*}{\multicolumn{4}{|c|}{$\begin{array}{c}1.9 \mu \mathrm{m} \\
\text { Test } \mathbf{i}\end{array}$}} & \multirow{2}{*}{\multicolumn{4}{|c|}{$\begin{array}{l}1.9 \mu \mathrm{m} \\
\text { Test_ii }\end{array}$}} & \multirow{2}{*}{\multicolumn{4}{|c|}{$\begin{array}{l}1.9 \mu \mathrm{m} \\
\text { Test_iii }\end{array}$}} & \multirow{2}{*}{\multicolumn{4}{|c|}{$\begin{array}{l}1.9 \mu \mathrm{m} \\
\text { Test iv }\end{array}$}} & & 1.9 & $\mu \mathrm{m}$ & \\
\hline & & & & & & & & & & & & & & & & & & & & & \\
\hline & Parameter & X/Omega & $\begin{array}{ll}\mathrm{Y} / \mathrm{Phi} \\
\end{array}$ & Z / Kappa & $\overline{X Y}$ & $\mathrm{X} /$ Omega & $\mathrm{Y} / \mathrm{Phi}$ & Z / Kappa & & $\mathrm{X} /$ Omega & Y/Phi & Z / Kappa & & $\mathrm{X} / \mathrm{Omeg}$ & $\mathrm{Y} / \mathrm{Phi}$ & Z / Kappa & $X Y$ & X/Omega & Y/Phi & Z / Kappa & $\mathrm{XY}$ \\
\hline$m$ & RMS Control & \begin{tabular}{|l|}
0 \\
\end{tabular} & 0.001 & \begin{tabular}{|l|}
0 \\
\end{tabular} & 0.001 & 0 & 0 & 0.001 & 0 & 0 & 0.001 & 0.003 & 0 & 0 & 0 & 0 & 0 & 0 & 0.001 & 0.003 & 0.001 \\
\hline 年 & RMS Check & 0.02 & 0.024 & 0.094 & 0.022 & 0.023 & 0.027 & 0.15 & 0.025 & 0.019 & 0.035 & 0.086 & 0.028 & 0.021 & 0.018 & 0.139 & 0.02 & 0.024 & 0.02 & 0.022 & 0.022 \\
\hline$\underline{\ddot{\Delta}}$ & RMS Limits & 0.04 & 0.04 & 0.04 & & 0.04 & 0.04 & 0.04 & & 0.04 & 0.04 & 0.04 & & 0.04 & 0.04 & 0.04 & & 0.04 & 0.04 & 0.04 & \\
\hline $\bar{\infty}$ & Max Ground Residual & 0 & 0.001 & 0.001 & & 0 & 0.001 & 0.001 & & 0.001 & 0.001 & 0.006 & & 0 & 0 & 0.001 & & 0.001 & 0.002 & 0.007 & \\
\hline & Mean Std Dev Object & 0.016 & 0.017 & 0.059 & & 0.016 & 0.017 & 0.062 & & 0.015 & 0.016 & 0.055 & & 0.017 & 0.019 & 0.062 & & 0.015 & 0.016 & 0.052 & \\
\hline & Sigma & & $1.3 \mu$ & & & & 1.3 & & & & 1.3 & & & & 1.3 & & & & & $\mu \mathrm{m}$ & \\
\hline & RMS Control & 0.002 & 0.001 & 0.001 & 0.002 & 0.01 & 0.004 & 0.006 & 0.008 & 0.007 & 0.008 & \begin{tabular}{|l|l|}
0.004 \\
\end{tabular} & 0.008 & 0.006 & 0.002 & 0.004 & 0.004 & 0.013 & 0.009 & 0.006 & 0.011 \\
\hline 0 & RMS Check & 0.053 & 0.044 & 0.17 & 0.049 & 0.049 & 0.041 & 0.143 & 0.045 & 0.064 & 0.032 & 0.123 & 0.05 & 0.05 & 0.041 & 0.104 & 0.046 & 0.031 & 0.037 & 0.091 & 0.034 \\
\hline 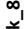 & RMS Limits & 0.04 & 0.04 & 0.05 & & 0.04 & 0.04 & 0.05 & & 0.04 & 0.04 & 0.05 & & 0.04 & 0.04 & 0.05 & & 0.04 & 0.04 & 0.05 & \\
\hline & Max Ground Residual & 0.004 & 0.001 & 0.002 & & 0.015 & 0.007 & 0.01 & & 0.014 & 0.016 & 0.007 & & 0.009 & 0.002 & 0.007 & & 0.024 & 0.016 & 0.013 & \\
\hline & Mean Std Dev Object & 0.017 & 0.02 & 0.062 & & 0.016 & 0.02 & 0.06 & & 0.016 & 0.02 & 0.06 & & 0.017 & 0.021 & 0.066 & & 0.015 & 0.019 & 0.058 & \\
\hline & Sigma & & $1.4 \mu$ & & & & 1.4 & & & & 1.4 & & & & 1.4 & & & & 1.4 & $\mu \mathrm{m}$ & \\
\hline & & & Test & & & & Tes & & & & Test & & & & Tes & & & & & t v & \\
\hline & Parameter & X/Omega| & $\begin{array}{l}/ P h i \\
\end{array}$ & Z / Kappa & $\overline{X Y}$ & $\mathrm{X} /$ Omega & $\mathrm{Y} / \mathrm{Phi}$ & Z / Kappa & $\overline{X Y}$ & X/Omega & Y/Phi & Z / Kappa & & $\mathrm{X} /$ Omeg & $\mathrm{Y} / \mathrm{Phi}$ & Z / Kappa & $\mathrm{XY}$ & $\mathrm{X} /$ Omeg & Y/Phi & Z / Kappa & $\mathrm{XY}$ \\
\hline m & RMS Control & 0.005 & 0.001 & 0.001 & 0.004 & 0.005 & 0.011 & 0.001 & 0.009 & \begin{tabular}{|l|}
0.01 \\
\end{tabular} & 0.005 & 0.006 & 0.008 & 0.007 & 0.004 & 0.006 & 0.006 & 0.008 & 0.01 & 0.005 & 0.009 \\
\hline & RMS Check & 0.027 & 0.03 & 0.051 & 0.029 & 0.027 & 0.019 & 0.056 & 0.023 & 0.02 & 0.024 & 0.058 & 0.022 & 0.028 & 0.028 & 0.055 & 0.028 & 0.017 & 0.019 & 0.062 & 0.018 \\
\hline$\stackrel{\check{\iota}}{\circ}$ & \begin{tabular}{|l} 
RMS Limits \\
\end{tabular} & 0.04 & 0.04 & 0.04 & & 0.04 & 0.04 & 0.04 & & 0.04 & 0.04 & 0.04 & & 0.04 & 0.04 & 0.04 & & 0.04 & 0.04 & 0.04 & \\
\hline & Max Ground Residual & 0.008 & 0.002 & 0.002 & & 0.01 & 0.023 & 0.002 & & 0.018 & 0.01 & 0.013 & & 0.016 & 0.007 & 0.013 & & 0.017 & 0.023 & 0.012 & \\
\hline & Mean Std Dev Object & 0.016 & 0.016 & 0.051 & & 0.016 & 0.015 & 0.049 & & 0.015 & 0.015 & 0.048 & & 0.015 & 0.015 & 0.049 & & 0.014 & 0.014 & 0.047 & \\
\hline & Sigma & & $1.3 \mu$ & & & & 1.3 & & & & 1.3 & & & & 1.3 & $\mu \mathrm{m}$ & & & 1.3 & $\mu \mathrm{m}$ & \\
\hline & RMS Control & 0.014 & 0.011 & 0.012 & 0.013 & 0.013 & 0.01 & 0.009 & 0.012 & 0.005 & 0.01 & 0.01 & 0.008 & 0.009 & 0.011 & 0.011 & 0.01 & 0 & 0 & 0.001 & 0 \\
\hline n & RMS Check & 0.039 & 0.04 & 0.152 & 0.039 & 0.043 & 0.043 & 0.135 & 0.043 & 0.045 & 0.035 & 0.128 & 0.04 & 0.044 & 0.036 & 0.122 & 0.04 & 0.039 & 0.036 & 0.092 & 0.038 \\
\hline & RMS Limits & 0.04 & 0.04 & 0.05 & & 0.04 & 0.04 & 0.05 & & 0.04 & 0.04 & 0.05 & & 0.04 & 0.04 & 0.05 & & 0.04 & 0.04 & 0.05 & \\
\hline ؛ & Max Ground Residual & 0.028 & 0.021 & 0.023 & & 0.022 & 0.017 & 0.013 & & 0.008 & 0.028 & 0.024 & & 0.024 & 0.027 & 0.021 & & 0.001 & 0 & 0.001 & \\
\hline & Mean Std Dev Object & 0.016 & 0.018 & 0.054 & & 0.016 & 0.017 & 0.053 & & 0.015 & 0.017 & 0.051 & & 0.015 & 0.017 & 0.051 & & 0.014 & 0.015 & 0.048 & \\
\hline & Sigma & & $1.5 \mu$ & & & & 1.5 & & & & 1.5 & & & & 1.5 & & & & 1.4 & $\mu \mathrm{m}$ & \\
\hline
\end{tabular}

The aero triangulation adjustment results found through using two different cameras and GNSS/IMU system have been compared with each other. Tab. 7 presents the positional and altitude errors in the check points as per three blocks and fifteen different configurations. Tab. 8 presents the maximum, minimum and mean absolute difference values in the check points of such blocks as well as the root mean square errors obtained from such points.

When Tab. 8 is reviewed in general by comparing the adjustment results obtained by using additional parameters within the residential and agricultural area blocks and the adjustment results, obtained by not using additional parameters within the forestland blocks, one sees that the additional parameters have improved the adjustment results in a significant way. It can be argued that within the blocks where the bundle adjustment was applied by self-calibration with additional parameters, the results obtained by using the class 5 GNSS/IMU receiver yielded more precise results than that of the class 4 receiver. As a result of the distribution of the ground control and check points based on block configurations, the closest result in terms of the ASPRS standards has been provided by the positional and altitude errors of the block 73 and block 33 that were obtained through the class $5 \mathrm{GNSS} / \mathrm{IMU}$ receiver. Especially the adjustment results in all versions of the block 33 are consistent with the ASPRS accuracy standards. When the block configurations are reviewed, however, it is seen that the configuration/test $\mathrm{v}$ has yielded more precise results within the photogrammetric block in terms of the distribution of the GCPs and check points (RMSxy and $\mathrm{RMS}_{\mathrm{Z}}$ ). As a result of this study, it is established that -of the data obtained through the DMCII-230 and UltraCam $\mathrm{XP}$ cameras and class 5 and class 4 IMU receivers and with respect to the accuracy verification of the photogrammetric triangulation adjustment- the blocks 33 and 103 within the agricultural test areas have yielded more accurate results than the residential areas (blocks 73 and block 86) while the residential areas have yielded more accurate results than the forestlands (block 9 and block 109). According to the camera calibration report on 
DMC II-230 dated 20.10.2014, the positional error for check points was anticipated as max. RMSx,y $\leq 0.32$ GSD, while the altitude error as max. RMSz $\leq 1.45$ GSD.
The results obtained from the block 9, block 109 and block 33 where the DMC II-230 was used are generally consistent with the designated error margin.

Table $7 \mathrm{RMS}_{\mathrm{xy}}$ and $\mathrm{RMS}_{\mathrm{z}}$ of blocks

\begin{tabular}{|l|c|c|l|c|c|}
\hline Block Name & RMSE $_{\mathbf{X Y}}(\mathbf{m})$ & $\mathbf{R M S E}_{\mathbf{z}}(\mathbf{m})$ & Block Name & $\mathbf{R M S E}_{\mathbf{X Y}}(\mathbf{m})$ & RMSE $\left._{\mathbf{z}} \mathbf{m}\right)$ \\
\hline Block_9_i & 0.13 & 0.15 & Block_109_i & 0.09 & 0.15 \\
\hline Block_9_ii & 0.14 & 0.14 & Block_109_ii & 0.09 & 0.1 \\
\hline Block_9_iii & 0.08 & 0.09 & Block_109_iii & 0.08 & 0.17 \\
\hline Block_9_iv & 0.13 & 0.15 & Block_109_iv & 0.09 & 0.15 \\
\hline Block_9_v & 0.11 & 0.09 & Block_109_v & 0.11 & 0.13 \\
\hline Block_73_i & 0.03 & 0.1 & Block_86_i & 0.07 & 0.17 \\
\hline Block_73_ii & 0.04 & 0.16 & Block_86_ii & 0.07 & 0.15 \\
\hline Block_73_iii & 0.07 & 0.08 & Block_86_iii & 0.07 & 0.13 \\
\hline Block_73_iv & 0.03 & 0.15 & Block_86_iv & 0.05 & 0.09 \\
\hline Block_73_v & 0.04 & 0.03 & Block_86_v & 0.04 & 0.1 \\
\hline Block_33_i & 0.03 & 0.1 & Block_103_i & 0.07 & 0.17 \\
\hline Block_33_ii & 0.03 & 0.06 & Block_103_ii & 0.06 & 0.1 \\
\hline Block_33_iii & 0.06 & 0.06 & Block_103_iii & 0.06 & 0.13 \\
\hline Block_33_iv & 0.04 & 0.06 & Block_103_iv & 0.06 & 0.1 \\
\hline Block_33_v & 0.03 & 0.06 & Block_103_v & 0.03 & 0.1 \\
\hline
\end{tabular}

Table 8 Maximum, minumum and mean differences of check points

\begin{tabular}{|c|c|c|c|c|c|c|c|c|c|c|c|}
\hline \multicolumn{7}{|c|}{ Block_9 } & \multicolumn{5}{|c|}{ Block_109 } \\
\hline & & Test_i & Test_ii & Test_iii & Test_iv & Test_v & Test_i & Test_ii & Test_iii & Test_iv & Test_v \\
\hline \multirow{3}{*}{ Max. } & $E$ & $0.1 \overline{5}$ & $0.1 \overline{5}$ & 0.11 & 0.17 & 0.13 & 0.11 & 0.13 & 0.09 & $0 . \overline{12}$ & 0.1 \\
\hline & $N$ & 0.29 & 0.29 & 0.27 & 0.27 & 0.19 & 0.11 & 0.09 & 0.13 & 0.1 & 0.08 \\
\hline & $H$ & 0.31 & 0.26 & 0.19 & 0.3 & 0.17 & 0.33 & 0.19 & 0.38 & 0.34 & 0.26 \\
\hline \multirow{3}{*}{ Min. } & $E$ & -0.15 & -0.15 & -0.07 & -0.09 & -0.09 & -0.11 & -0.09 & -0.09 & -0.11 & -0.06 \\
\hline & $N$ & -0.06 & -0.09 & -0.07 & -0.08 & -0.08 & -0.11 & -0.09 & -0.13 & -0.1 & -0.08 \\
\hline & $H$ & -0.23 & -0.23 & -0.07 & -0.11 & -0.03 & -0.21 & -0.2 & -0.18 & -0.09 & -0.13 \\
\hline \multirow{3}{*}{ Mean } & $E$ & 0.06 & 0.08 & 0.05 & 0.06 & 0.06 & 0.05 & 0.06 & 0.04 & 0.05 & 0.03 \\
\hline & $N$ & 0.08 & 0.07 & 0.08 & 0.07 & 0.06 & 0.05 & 0.04 & 0.06 & 0.04 & 0.04 \\
\hline & $H$ & 0.12 & 0.11 & 0.07 & 0.12 & 0.07 & 0.12 & 0.08 & 0.13 & 0.12 & 0.09 \\
\hline \multirow{3}{*}{ RMS } & $E$ & 0.076 & 0.089 & 0.059 & 0.078 & 0.072 & 0.064 & 0.073 & 0.051 & 0.068 & 0.05 \\
\hline & $N$ & 0.11 & 0.11 & 0.113 & 0.105 & 0.08 & 0.058 & 0.048 & 0.067 & 0.053 & 0.055 \\
\hline & $H$ & 0.151 & 0.137 & 0.09 & 0.148 & 0.091 & 0.151 & 0.099 & 0.172 & 0.154 & 0.132 \\
\hline \multicolumn{7}{|c|}{ Block 73} & \multicolumn{5}{|c|}{ Block_86 } \\
\hline & & Test_i & Test_ii & Test_iii & Test_iv & Test_v & Test_i & Test_ii & Test_iii & Test_iv & Test_v \\
\hline \multirow{3}{*}{$\operatorname{Max}$} & $E$ & 0.11 & 0.13 & 0.09 & 0.12 & 0.1 & 0.11 & 0.13 & 0.09 & 0.12 & 0.1 \\
\hline & $N$ & 0.11 & 0.09 & 0.13 & 0.1 & 0.08 & 0.11 & 0.09 & 0.13 & 0.1 & 0.08 \\
\hline & $H$ & 0.33 & 0.19 & 0.38 & 0.34 & 0.26 & 0.33 & 0.19 & 0.38 & 0.34 & 0.26 \\
\hline \multirow{3}{*}{ Min } & $E$ & -0.11 & -0.09 & -0.09 & -0.11 & -0.06 & -0.11 & -0.09 & -0.09 & -0.11 & -0.06 \\
\hline & $N$ & -0.11 & -0.09 & -0.13 & -0.1 & -0.08 & -0.11 & -0.09 & -0.13 & -0.1 & -0.08 \\
\hline & $H$ & -0.21 & -0.2 & -0.18 & -0.09 & -0.13 & -0.21 & -0.2 & -0.18 & -0.09 & -0.13 \\
\hline \multirow{3}{*}{ Mean } & $E$ & 0.05 & 0.06 & 0.04 & 0.05 & 0.03 & 0.05 & 0.06 & 0.04 & 0.05 & 0.03 \\
\hline & $N$ & 0.05 & 0.04 & 0.06 & 0.04 & 0.04 & 0.05 & 0.04 & 0.06 & 0.04 & 0.04 \\
\hline & $H$ & 0.12 & 0.08 & 0.13 & 0.12 & 0.09 & 0.12 & 0.08 & 0.13 & 0.12 & 0.09 \\
\hline \multirow{3}{*}{ RMS } & $E$ & 0.064 & 0.073 & 0.051 & 0.068 & 0.05 & 0.064 & 0.073 & 0.051 & 0.068 & 0.05 \\
\hline & $N$ & 0.058 & 0.048 & 0.067 & 0.053 & 0.055 & 0.058 & 0.048 & 0.067 & 0.053 & 0.055 \\
\hline & $H$ & 0.151 & 0.099 & 0.172 & 0.154 & 0.132 & 0.151 & 0.099 & 0.172 & 0.154 & 0.132 \\
\hline \multicolumn{7}{|c|}{ Block 33} & \multicolumn{5}{|c|}{ Block_103 } \\
\hline & & Test_i & Test_ii & Test_iii & Test_iv & Test_v & Test_i & Test_ii & Test_iii & Test_iv & Test_v \\
\hline \multirow{3}{*}{ Max } & $E$ & 0.06 & 0.07 & 0.05 & 0.06 & 0.04 & 0.09 & 0.09 & 0.08 & 0.09 & 0.09 \\
\hline & $N$ & 0.1 & 0.06 & 0.08 & 0.08 & 0.04 & 0.08 & 0.07 & 0.08 & 0.07 & 0.07 \\
\hline & $H$ & 0.1 & 0.11 & 0.12 & 0.11 & 0.12 & 0.39 & 0.22 & 0.32 & 0.22 & 0.22 \\
\hline \multirow{3}{*}{ Min } & $E$ & -0.06 & -0.05 & -0.03 & -0.06 & -0.03 & -0.09 & -0.03 & -0.06 & -0.03 & -0.03 \\
\hline & $N$ & -0.1 & -0.03 & -0.08 & -0.08 & -0.03 & -0.08 & -0.06 & -0.04 & -0.06 & -0.06 \\
\hline & $H$ & -0.09 & -0.07 & -0.04 & -0.03 & -0.04 & -0.17 & -0.15 & -0.08 & -0.08 & -0.08 \\
\hline \multirow{3}{*}{ Mean } & $E$ & 0.02 & 0.03 & 0.04 & 0.03 & 0.03 & 0.03 & 0.03 & 0.04 & 0.03 & 0.03 \\
\hline & $N$ & 0.02 & 0.03 & 0.03 & 0.03 & 0.03 & 0.03 & 0.03 & 0.03 & 0.03 & 0.03 \\
\hline & $H$ & 0.04 & 0.08 & 0.1 & 0.08 & 0.08 & 0.12 & 0.08 & 0.1 & 0.08 & 0.08 \\
\hline \multirow{3}{*}{ RMS } & $E$ & 0.027 & 0.027 & 0.021 & 0.028 & 0.017 & 0.033 & 0.041 & 0.046 & 0.041 & 0.041 \\
\hline & $N$ & 0.023 & 0.019 & 0.024 & 0.029 & 0.019 & 0.039 & 0.038 & 0.036 & 0.038 & 0.038 \\
\hline & $H$ & 0.025 & 0.057 & 0.059 & 0.057 & 0.063 & 0.096 & 0.095 & 0.132 & 0.095 & 0.095 \\
\hline
\end{tabular}

\section{CONCLUSION}

Three blocks chosen based on their respective terrain class have been tested in five different test areas that were planned in accordance with the distribution of the ground control points within the block. The main criteria of this study are the establishment of the differences of the GNSS/IMU systems and the distribution of the ground control points within the block. As a conclusion, it can be argued that the close proximity of the camera focus distances, similar flight altitude values and similar results achieved with the images captured with the DMCII-230 
and UltraCamXP cameras in terms of ground sampling distance has a bearing on the results that may be obtained through different GNSS/IMU systems. Moreover, the number and distribution of the ground control points within the photogrammetric block have an effect on the results as well. Owing to the fact that the blocks were small in the block adjustment and that the flight altitude was low (about 1650 meters), the results of selfcalibrating with additional parameters bundle adjustment seem to be adequate As a result of this study, it has been established that, according to the terrain classification, the photogrammetric triangulation adjustment accuracy is most ideally presented, in terms of point distribution, in such geodesic structures as the block corners, edges and the block center.

\section{Acknowledgement}

This study was prepared from Ahmet GÜNTEL master thesis, the name of which is "Effect of Different GPS/IMU Systems for Aireal Triangulation". This thesis was completed in Natural and Applied Science Institute of Selcuk University in Department of Geomatics Engineering in 2015.

\section{REFERENCES}

[1] Ackermann, F. (1991). GPS for photogrammetry. Tutorial on Mathematical Aspects of Data Analysis. ISPRS ICWG III/VI, 17-70

[2] Alamus, R., Kornus, W., \& Talaya, J. (2006). Studies on DMC geometry. ISPRS Journal of Photogrammetry and Remote Sensing, 60, 375-386. https://doi.org/10.1016/j.isprsjprs.2006.05.006

[3] Berveglieri, D. \& Tommaselli, M. G. A. (2015). Locating control points in aerial images with a multi-scale approach based on terrestrial image patches. The Photogrammetric Record, 30(149), 63-81. https://doi.org/10.1111/phor.12096

[4] Bilker, M., Honkavaara, E., \& Jaakkola, J. (1998). GPS supported aerial triangulation using untargeted ground control. ISPRS Commission III Symposium "Object Recognition and Scene Classification from Multispectral and Multi-sensor Pixels", July 6-10, 1998, Columbus, Ohio. Schenk, T. and A. Habib (eds), International Archives of Photogrammetry and Remote Sensing, 32(3/1), 2-9.

[5] Casella, V., Franzin, M., Kocaman, S., \& Gruen, A. (2008). Geometric accuracy assessment of ADS40 imagery under various network configurations. 21 $1^{\text {th }}$ ISPRS Congress, 3-7 July, 2008, Beijing, Vol. 37, Part B1-2, 627-632.

[6] Casella, V., Franzini, M., \& Padova, B. (2007). Accuracy assessment of ADS40 imagery as a function of flying height and of aerial triangulation strategies. ISPRS Archives, Vol. XXXVI-5/C5, The $5^{\text {th }}$ International Symposium on Mobile Mapping Technology MMT '07, May 29-31, Pradua, Italy.

[7] Chiang, K-W, Tsai, M-L., \& Chu, C-H. (2012). The Development of an UAV Borne Direct Georeferenced Photogrammetric Platform for Ground Control Point Free Applications. Sensors, 12, 9161-9180. https://doi.org/10.3390/s120709161

[8] Cramer, M., Stallmann, D., \& Haala, N. (2002). Direct georeferencing using GPS/Inertial exterior orientations for photogrammetric applications. IASPRS, Vol. XXXIII, Amsterdam.

[9] Gneeniss, A. S., Mills, J. P., \& Miller P. E. (2011) Assessment of ULTRACAMD performance in an arid environment case study in Libya. International Archives of the Photogrammetry, Remote Sensing and Spatial Information Sciences, Volume XXXVIII-4/W19, ISPRS 2011 Workshop, 14-17 June 2011, Hannover, Germany.

[10] Habib, A. \& Kersting, A. P. (2010). Analysis of control and flight configuration requirements for mounting parameters calibration of GPS/INS assisted photogrammetric systems, http://www.isprs.org/proceedings/XXXVIII/part1/03/03_05 Paper 42.pdf

[11] Honkavaara, E., Ahokas, E., Hyyppä, J., Jaakkola, J., Kaartinen, H., Kuittinen, R., Markelin, L., \& Nurminen, K. (2006). Geometric test field calibration of digital photogrammetric sensors. ISPRS Journal of Photogrammetry and Remote Sensing, 60, 387-399. https://doi.org/10.1016/j.isprsjprs.2006.04.003

[12] Hutton, J. \& Mostafa, M. M. R. (2005). 10 years of direct georeferencing for airborne photogrammetry, Photogrammetric Week

[13] Ip, A. W. L. (2005). Analysis of integratedsensor orientation for aerial mapping, Master Thesis, University of Calgary, UCGE Reports, Number 20204.

[14] Awange, J. L. \& Kyalo Kiem, J. B. (2013). Chapter11Fundamentals of Photogrammetry, Environmental Geoinformatics, 157 Environmental Science and Engineering, (C) Springer-Verlag Berlin Heidelberg. https://doi.org/10.1007/978-3-642-34085-7_11

[15] Jacobsen, K. (2011). Recent developments of digital cameras and space imagery, GIS Ostrava.

[16] Jacobsen, K. \& Neumann, K. (2012). Property of the large format digital aerial cameras DMC II. International Archives of The Photogrammetry, Remote Sensing and Spatial Information Sciencies, Vol. XXXIX-B1, XXII ISPRS Congress, 25 August-01 September 2012, Melbourne, Australia. https://doi.org/10.5194/isprsarchives-XXXIX-B1-21-2012

[17] Kim, B. O., Yun, K-H., \& Lee, C-K. (2014). The use of elevation adjusted ground control points for aerial triangulation in coastal areas. KSCE Journal of Civil Engineering, 18(6), 1825-1830. https://doi.org/10.1007/s12205-014-0390-9

[18] Lembicz, B. W. (2006). Minimizing ground control when GPS photogrammetry isn't practical. ASPRS 2006 Annual Conference, Reno, Nevada, May 1-5, 2006

[19] Munjy, R. \& Hussain, M. (2010). Standards for block configuration airborne GPS controlled photogrammetry for large scale mapping project, Final Project Report, March $15,2010$.

[20] Passini, R., Jewell, D., \& Jacobsen, K. (2002). An accuracy study on a large airborne GPS aero triangulation block. ASPRS Annual Convention, Washington, 2002

[21] Shen, X. (2015). Accurate direct georeferencing of aerial imagery in national coordinates. ISPRS Journal of Photogrammetry and Remote Sensing, 105, 13-18. https://doi.org/10.1016/j.isprsjprs.2015.03.008

[22] Skaloud, J. (2007). Reability of directgeoreferencing beyondthe Achilles heel of modern airborne mapping. Photogrammetric Week'07, Germany, 227-241

[23] Skaloud, J. \& Legat, K. (2008). Theory and reality of direct georeferencing in national coordinates. ISPRS Journal of Photogrammetry and Remote Sensing, 63, 272-282. https://doi.org/10.1016/j.isprsjprs.2007.09.002

[24] Tachibana, K., Gruber, M., \& Shimamura, H. (2008). Geometric accuracy investigation of VEXCEL ULTRACAMD. The International Archives of The Photogrammetry, Remote Sensing and Spatial Information Sceinces, Vol. XXXVIII. Part. B1. Beijing, 2008

[25] Yastıkl1, N. \& Jacobsen, K. (2005). Direct sensor orientation for large scale mapping-Potential, problems, solutions. Photogrammetric Record, 20(111), 274-284. https://doi.org/10.1111/j.1477-9730.2005.00318.x 
[26] Yuan, X. (2000). Principle, software and experiment of GPS-supported aero triangulation. Geo-Spatial Information Science, 3(1), 24-33. https://doi.org/10.1007/BF02826803

[27] Yuan, X. (2008). A novel method of systematic error compensation for a position and orientation. Progress in Natural Science, 18, 953-963. https://doi.org/10.1016/j.pnsc.2008.02.005

[28] Yuan, X., Fu, J., Sun, H., \& Toth, C. (2009). The application of GPS precise point positioning technology in aerial triangulation. ISPRS Journal of Photogrammetry and Remote Sensing, 64, 541-550.

https://doi.org/10.1016/j.isprsjprs.2009.03.006

[29] Yun, K. H. \& Kim, B. (2014). Investıgatıng the Accuracy of Aerial Triangulation on the Baeksajang Beach. 35th Asian Conference on Remote Sensing, Nay Pyi Taw, Myanmar 27-31 October 2014

[30] Ziobro, J. (2012). Integrated sensor orientation- ground control pioints for a large-block aerotriangulation. Geoinformation Issues, 3(1), 37-45.

\section{Contact information:}

Ahmet GUNTEL, MSc

Mescioglu Engineering and Consultancy Inc.

Ankara, Turkey

E-mail: aguntel@mescioglu.com.tr

Hakan KARABORK, PhD, Professor

Selcuk University

Faculty of Engineering

Department of Geomatics Engineering

Konya, Turkey

E-mail: hkarabork@selcuk.edu.tr

Lutfiye KARASAKA, PhD, Assistant Professor

Selcuk University

Faculty of Engineering

Department of Geomatics Engineering

Konya, Turkey

E-mail: lutfiye@selcuk.edu.tr 